\title{
Ambient Robotics for Meaningful Life of the Elderly
}

\author{
Joohyun Chung \\ Architectural Department, Seoul National University, Seoul 426-812, Korea
}

\begin{abstract}
It is innovative if people can be free from aged body and continue their career with assistance of robotics. It is supposed to see the change soon as smart phone changed life style. This research aims to figure out the direction of this change, development in technique for elders. It also studies various theories to justify various methods for ambient assistance robotic design for elders. In the long life expectancy world, this design will enhance the life quality of elders and encourage young people get pride in their own job, because their career will continue and it deserves to invest all their energy and sincerity in a specific area. As ambient robotics are a design for elders' adjacent assistive design and part of everyday, it is related with quality of elders' life. Some theories are cited for the importance of meaningful life. Meaningfulness is regarded as the fundamental goal of design purpose, because meaning stands upon the concept of human being and its consciousness activity. Phenomenological background of this research is introduced. It can be suggested in field observation to get real stories containing meanings and essence of life of elders. In conclusion, this study is a beginning of long process to prepare aging society with technique as well as perspective to see elders as valuable work force.
\end{abstract}

Key words: Aging society, meaningful life, phenomenology, ambient robotics.

\section{Introduction}

We call aging society if the aging index is $7 \%$. And $14 \%$ is for the aged society.

Table 1 shows the ratio of the old over 65 years old compared to the young under 14 years old. Some European and American countries began aging society early like 19th century and it took over a century or decades from aging society to aged one. But Japan and Korea has the problem of shorter duration like 7 years and 12 years. World is aging and soon become aged, but it is doubtful if aged people can contribute to the society and have proper self-respect. About employment ratio of age between 55 and 64 in leading countries of the world shows $60 \%$ or $70 \%$.

If a man leaves his workplace around 50, it means that he is far away from society over 20 or 30 years. It is so undesirable that someday he will be resigned and his career will be stopped. It can be applied to various careers, too. We work for 30 or 40 years and remain as a retiree for almost same years.

This work regards the elderly not only beings to care

Corresponding author: Joohyun Chung, Dr., research fields: architectural planning and theory. E-mail: joohyunchung@snu.ac.kr. for but also ones to live meaningfully and continue their career. It is not only the matter of self-realization and to keep human dignity, but also important human resources exclusion from society.

In other aspects, elders who accumulated experience and wisdom should be used in society. Elders are a group in a society who are usually retired from jobs and have long experience as a social member. According to WHO (World Hospital Organization), people retire usually around between 50 and 60 , and life expectancy is 80 years. It means that they have over 30 years' experience and still around 20 years' life. It is regretful to hoard human resource uselessly for individual and for society.

A controversy about employment competition with the younger generation can happen. It is another challenge if the elderly still demonstrate their capability in the practical field, therefore, it should be investigated in another paper. In this research, mainly the stance of elderly will get attention.

The object of this study is to investigate the direction of the innovative development ambient robotic design process for the elderly upon phenomenological perspective. This objectivity will 
Table 1 Future population estimating [1].

\begin{tabular}{|c|c|c|c|c|c|}
\hline \multirow{2}{*}{ Country } & \multicolumn{3}{|c|}{ Reached year } & \multicolumn{2}{|c|}{ Changed duration (year) } \\
\hline & $\overline{7 \%}$ & $14 \%$ & $20 \%$ & $7 \% \rightarrow 14 \%$ & $14 \% \rightarrow 20 \%$ \\
\hline Korea & 2000 & 2019 & 2026 & 19 & 7 \\
\hline Japan & 1970 & 1994 & 2006 & 24 & 12 \\
\hline France & 1861 & 1979 & 2020 & 115 & 41 \\
\hline Germany & 1932 & 1972 & 2012 & 40 & 40 \\
\hline UK & 1929 & 1976 & 2021 & 47 & 45 \\
\hline Italy & 1927 & 1988 & 2007 & 61 & 19 \\
\hline USA & 1942 & 2013 & 2028 & 71 & 15 \\
\hline
\end{tabular}

fulfill the aim to show real object of ambient robotics, not only techniques but also contribution to desirable life quality. It is definitely the latest technique, which is not only passive reaction to assist the weak physical condition of the elderly, but also to figure out how the technique can contribute to human prestige. With the development of techniques like gene engineering, medical techniques and cut-edged telecommunication like smartphone and internet, life cycle becomes longer. In addition, ambient robotics for aged people are one of the rising issues for increasing the elderly: ambient robotics are designed to help elders' inconvenient behavior in everyday life like shower and cooking. Elders can enjoy self-regulating life, for example, they can also continue their professional career and achieve self-relization through work. It would be hopeful to keep good condition with proper treatment like food and exercise, and health investigation, but it would be so desirable also to get artificial assistance.

Phenomenological reflection is one of main methodologies of this paper. Because technique should not be developed alone, but it should be a part of whole life world changing. Life world is a concept from phenomenology. Transcendental subjectivity of phenomenology is the foundation of meaning owner. Some researches show the importance of meaning in life, not only psychologically but also socially and physically. Therefore, this paper supposes meaningful life as an impetus for technical development. In other words, life cycle is getting longer, but we do not want just longer life, but also valuable one. We need quantitative methods as well as qualitative ones to reach the balanced methodology of development. Literature investigation about life quality improvement and real good results will guarantee and elaborate all the ideas why we should reflect on the meaning of life and identity of elders.

\section{Aging Society and Related Researches}

For this research, references for aging society, academic journal, statistical analysis report and mass media were reviewed. Mass media shows changed attitude of elders who want to realize themselves, but it is not easy to find academic researches about elders' self-realization and career continuity. Healing environment for the elderly is the main issue for the old. Pathological and sensual research is also one part of assistive space design for the elderly. They insist on preparing for aging-society and study about gerontology or elders' welfare. In short, to the most of experts, elders are weak beings who need care, not to have self-determination.

To study about healing environment for elders is very important for human right, like suggestions for passive green space, wandering areas for those with dementia and enough residence and community for lonely elders.

Healing of elderly housing has objectives like the physical stability and psychological stability. Moon [2] talks that human dignity is the most important healing environment factors in health and welfare facilities. Privacy can be the psychological factor to keep dignity. Environmental and social aspects require intimacy and familiarity. In terms of environmental and hygienic 
environment, good scenery, including the introduction of audio-visual art, is required. After all, these factors are associated with stress reduction. To design stress-free facility is absolutely important, but it might be possible to go further from passive reaction to active attempt, from not stressful space to self-realizing environment.

Recently, neurologists also insist that elderly healthcare facility should have healing environment for immunology (psychoneuroimmunology) According to the study, the emotional stress will have an effect on the immune function of patients. German interior architect Monz [4] argued that the positive emotions can lead to improve the health of patients. There is another kind of research that does not remain in the passive reaction but goes further to face with enterprising spirit. Ambient robotics for elders is a case of good research to actualize meaningful life.

Fig. 1 shows the way to design ambient robotics. Georgoulas et al. [5] have researched and designed robots hidden in the familiar furniture. There are hidden sensors and telecommunication system directed to medical facility [5]. Yellow uniform has sensors in the red line and sends behavioral or physical change data to computer. Because it is hidden in furniture or combined to wall or door, there is no hindrance for every day but it assists weak physical function of elders. It is not to create new facility, but use existing furniture with cut-edged system. We can feel comfortable at familiar environment. This experiment is to match daily behavior to hidden sensors in furniture.

Fig. 2 shows an example of innovative ambient robotics design, without mechanic and artificial occupation in room, elders can get help to move. A hanger is clung to ceiling and moves a man without space occupation. It is expected to reduce inconvenient feeling by machine and we can regard us as self-controlling beings, even though we are assisted by instruments.

Figs. 1 and 2 are one of ambient assistance design
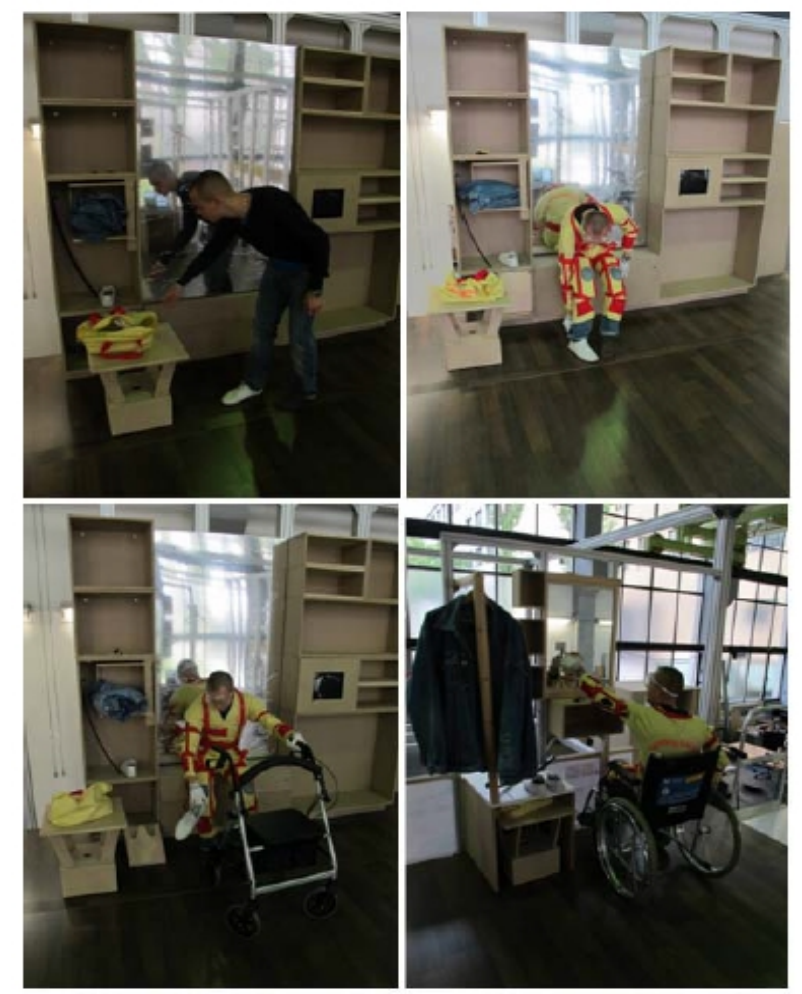

Fig. 1 Evaluation of the robotic furniture system by an age simulation suite.

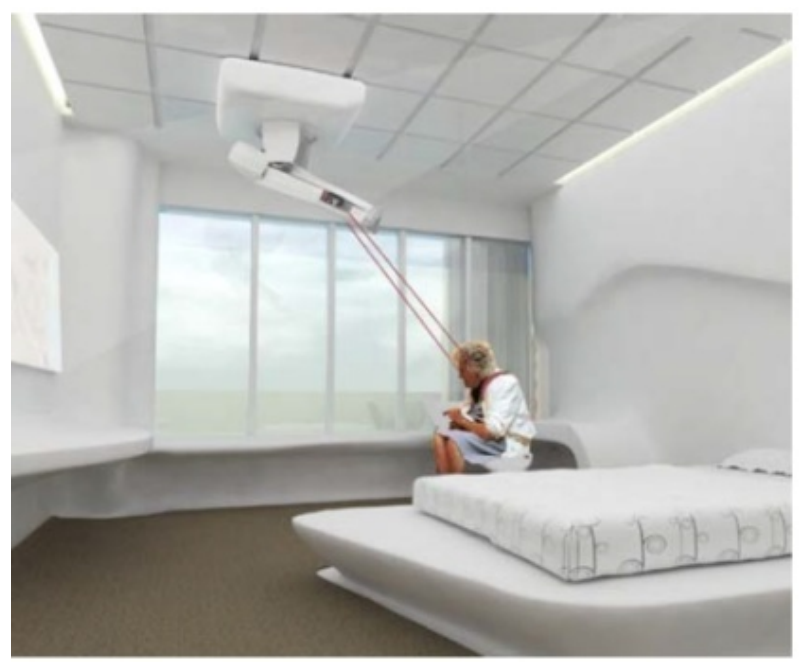

Fig. 2 Functional transfer assistant [6].

results. Another ambient assistance research is done or still on progress by various categories like architectural elements, elders' behavior patterns and special instrument development.

Fig. 3 shows a kitchen modular design by cooking process. Modular design is flexible and productive [7]. Not only general adaptation with modular, but also 


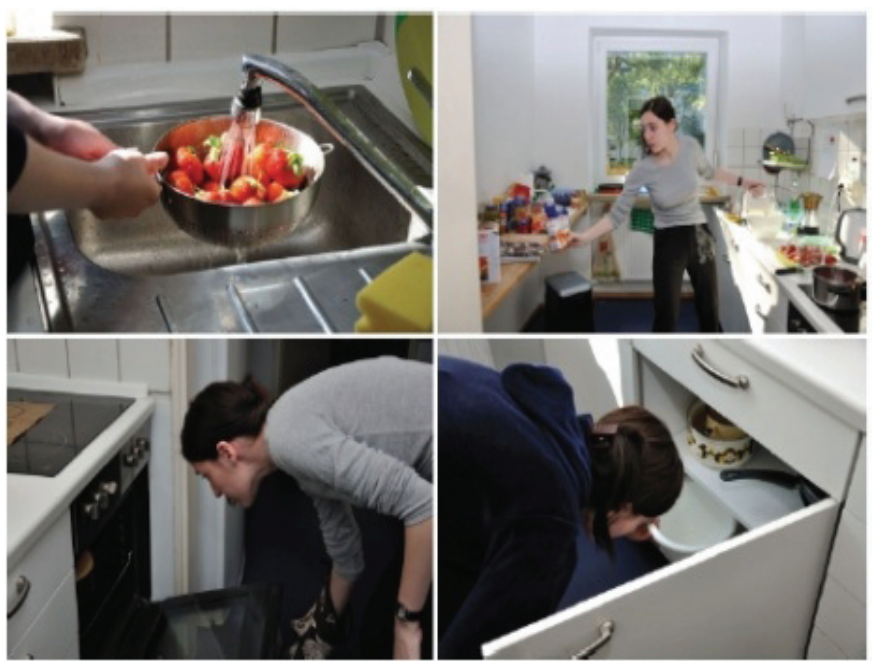

(a)

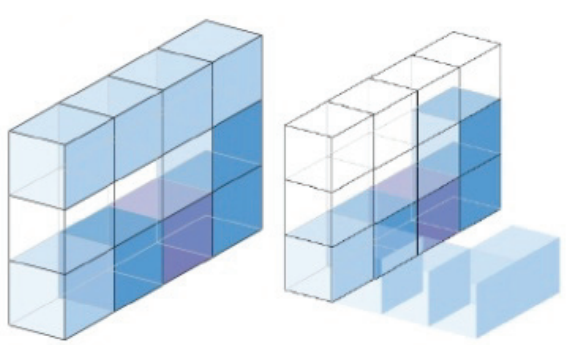

Fixed installation tile, plumbing installation or water supply (sink, (dish-)washing machine, etc.)

Rubik kitchen concept

Semi-fixed installation tile, complicated but possible to move (integrated small electrical appliances, fridge, oven, etc.) Rubik kitchen concept

Flexible tile, independent movement (storage) Rubik kitchen concept

(b)

Fig. 3 (a) Cooking process experiment; (b) modular arrangement according to the process.

special instrument can assist elders' inconvenient actions. When our physical ability is perfect, every process in kitchen is simple, but even a little weakness in a body reminds us that activities in kitchen are very complex. Module is a tool to be flexible to apply to all moving and to modify systems according to each individual.

Fig. 4 shows another case of modular room but different from Fig. 3 [5]. All required functions such as beds, sofas, tables and chairs can be integrated into system, so the old can do various activities easily at one place. It is required to think differently when some activities become inconvenient when we get old. It does not mean that we became weak and handicapped, because a little design modification of living room and work room can enhance space usage ability. Sensors of Fig. 1 are also applied in the integrated furniture of Fig. 4.

Fig. 5 shows an image of special bathtub for elders. Even young people can feel dizzy during hot water shower. If a man is slipped on the wet floor, it is so dangerous. This facility reduces any case of falling down, because the old can lean on the bathtub when it is not easy to stand for a while. A little gesture to put technical and mechanical protection eradicates accidents in a bathroom. Failure in basic activity in every day cannot disappoint anyone with this assistive solution.

Ambient robotics should not be understood as a medium, because it is integrated into existing things, and not perceptible part of everyday life. We cannot perceive the being of the air, but we cannot live without it. Ambient robotics also will not get our attention in the life world like air. Because people have spiritual aspect as well as physical, for the real healing

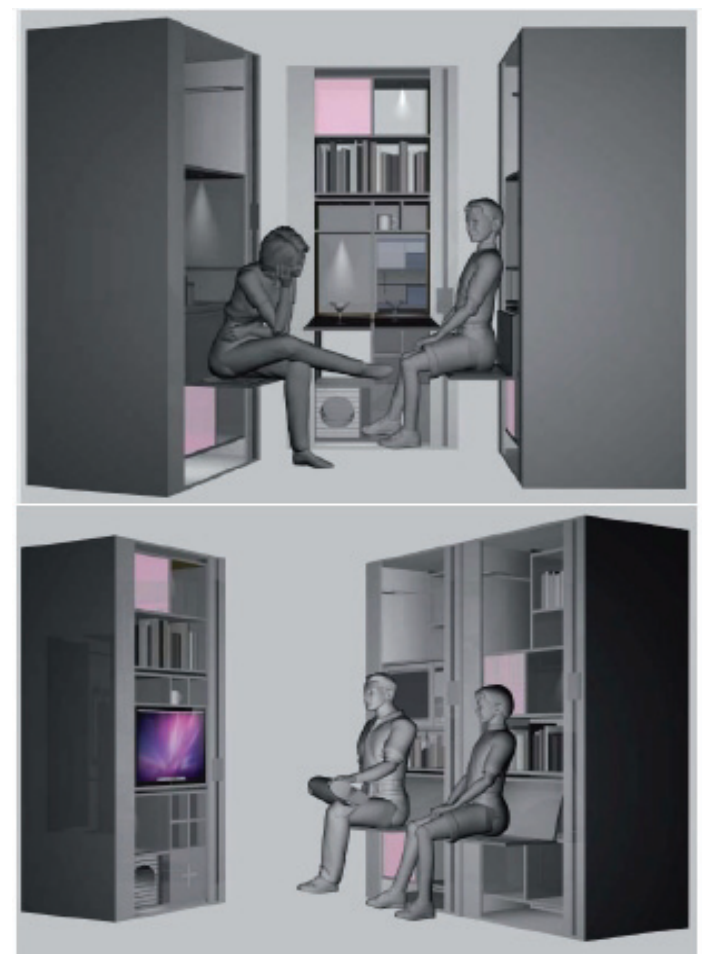

Fig. 4 Proposed concept configurations. 

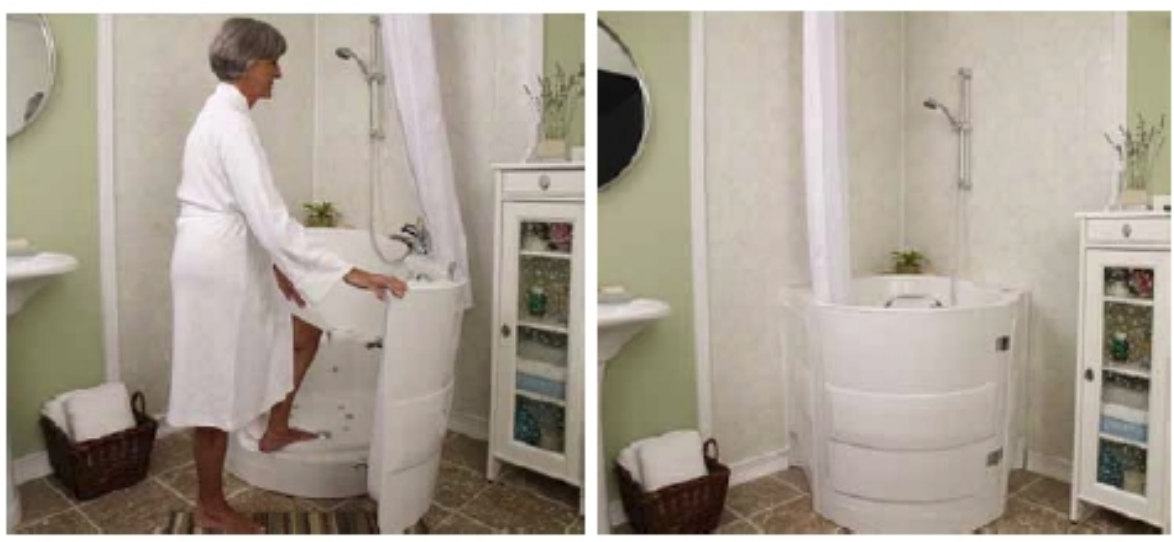

Fig. 5 Bathing assistive solution [8].

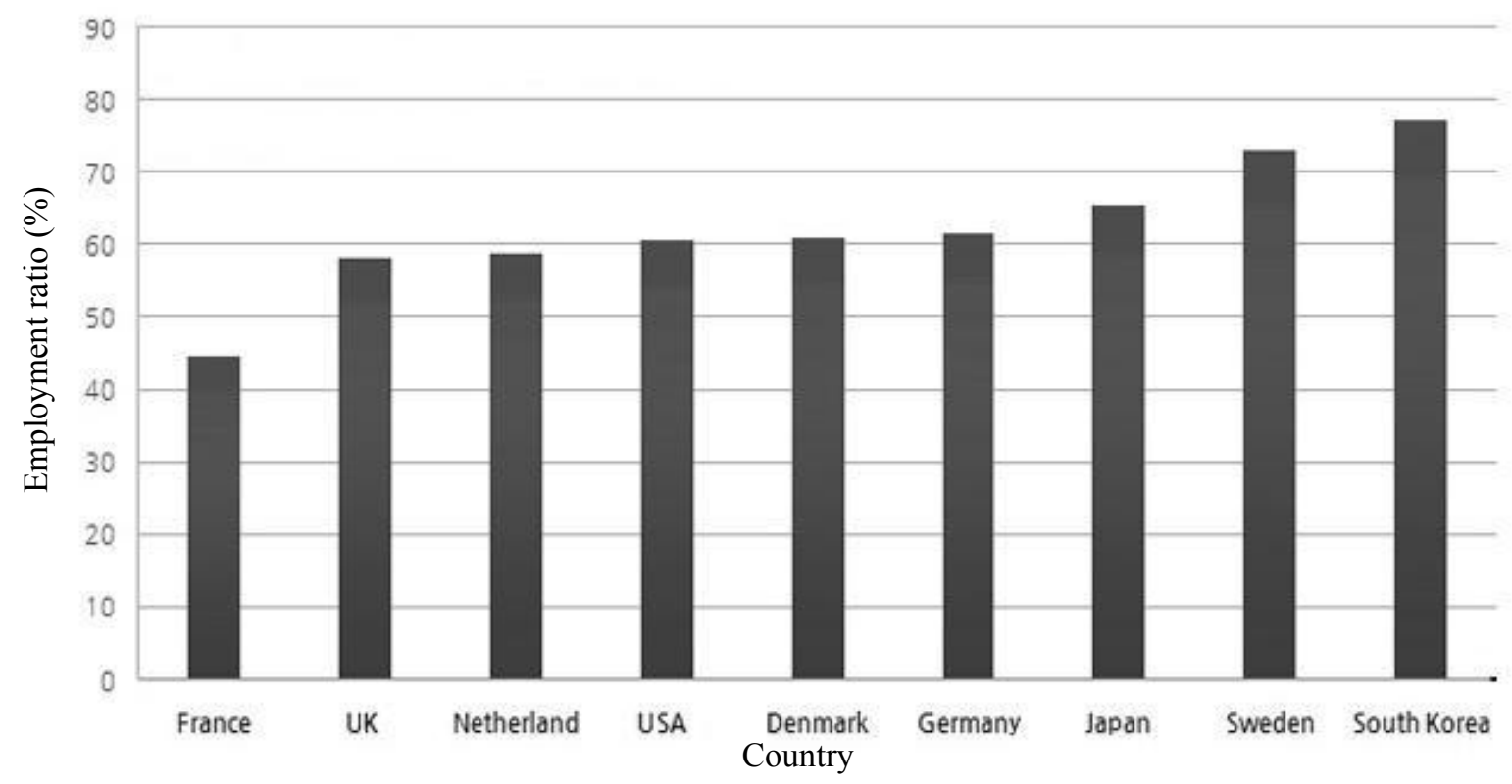

Fig. 6 Employment ratio (\%) of age between 55 64 [9].

environment for the seniors, the balance between function and meaning should be kept and architectural field should be developed based on the growth in technique and humanities. It is necessary not only to think about how to develop techniques, but also to reflect upon the reason why do we need ambient robotics and what do they mean to our lives. Reflection before big change by technique will guarantee us to save time and cost.

A graph is composed to show employment ratio of age between 55 64. Fig. 6 shows that considerable seniors between 55 and 64 are not employed: South Korea and Denmark have over $70 \%$ ratio, but other countries except two are $60 \%$ or $50 \%$. The elders are usually long-trained so it would be wasteful to bury their experience. There should be proper research methodology to use latent and skilled professionals. They do not need care facilities, but they need position where their activity can gain recognition. This perspective is another perspective to bring elders a healthier and dynamic life. It is not only for elders but also for next generation.

When people look for jobs, they consider usually working period, retirement of their profession, and high earning efficiency. Pension is the final hope of desirable life in their old time. If work experience in 
young age affects old age career, then work efficiency of young people will also rise. Therefore, research to assist for elders' vocational ability should be done.

\section{Theoretical Background for Methodology}

\subsection{Life World}

We need to know the holistic meaning of a given surrounding. The perspective of aged individuals is essential in finding out what the holistic meaning of their surrounding is. The goal is to be able to observe a situation without prejudice and develop the most appropriate method for analyzing these types of situations. Individual perspectives could be observed and interviewed, and this direct experience is belonged to qualitative research comparing to quantitative one. For example, about statistics of birth rate and life expectancy, we depend on quantitative analysis, but ethnicity or national characteristics can be investigated by direct experience like observation and description. Life quality of the old cannot be explained only by quantitative result: we need qualitative study about value, priority and justification in life.

Each person has different ways of remembering and formulating their points of view. By using Husserl's phenomenological epoche and suspending our tendency to form judgments, research can be established more clearly. He or she will compare previous analysis methods and develop various methods for organizing data. Having a flexible procedure based on sound experiential principles is an essential phenomenological idea. Specialists in the humanities as well as medical technicians and nurses will participate in seminar discussions and otherwise provide insightful feedback for the research.

To receive the correct knowledge, a variety of means of communication is desirable. At the research scene, researchers need to be flexible in attitudes. They might be objective researchers as well as they should be daughter or friend of the elderly. This flexible attitude gives us more clear essence. Phenomenological reduction is achieved by stopping the judgment. This is general formulation of the natural attitude to stop the judge. In day-to-day life, we take the natural attitude. Although each individual experiences the world to be illusion or hallucination, even if that number is revealed that even while maintaining the unity we believe to exist. The scope of the navigation is reduced through the reduction and exclusion. It does not preclude that determines what the problem is.

In the radical developments of technique, we have abundant data. Now, it is time to know the meaning of the change. Theoretical background provides researchers with the perspective and methodology about how to approach to the problem. This research stands on the theoretical background of phenomenology. In phenomenology, transcendental subjectivity constitutes meaning in the life world. It takes time to constitute a meaning as it takes time to build a story or to go through a procedure. The story is made not only by causal relationship but also by non-casual intentionality [10]. According to Husserl [11], the meaning is noema and the intending meaning is noesis. This noesis can be meaningless but intuition is adequate to the noema. On the epistemological level, lived experience (erlebnis) is, in phenomenology, the primary source of knowledge, but non-intuitional (e.g., scientific) perspectives as a part of the life world are also taken into account.

Life world is a concept from phenomenology. Technique should not be developed alone, but it should be a part of the whole life world changing. Then what can be the driving force for aging society? This paper supposes meaningful life as an impetus for technical development. We do not want just longevity, but also virtue in life. We can think with phenomenology and its methodology: qualitative methods like narrative, interview, observation or non-verbal methods like sketches.

On the ontological level, phenomenology acknowledges the foundational character of the life world. The concept of life world implies an epistemology in which the question of meaning is most 
important: the life world is the ultimate horizon for all cognitive activities. As Husserl puts it, "The concrete life-world is the grounding soil of the 'scientifically true' world and at the same time encompasses its own universal concreteness" [12]. Heidegger [13] is a philosopher who tried to understand and explain human being. He analyses the meaning of dwelling in relation to ontology. According to him, to be a human being means to be on the earth, in other words, they dwell in the world.

According to Sirowy [3], "phenomenology approaches philosophical inquiry from a different perspective, addressing the phenomenon of the world in terms of its being the determinate for the ontological meaning of all the entities within it, and not just something which is determined by them". As Heidegger [13] emphasizes, we always refer to things as being "within the world", and this indicates that we have an intuitive understanding of the world, as coming before the notion of the things which are present within it. We understand ourselves and things in terms of the world. The world, however, is not the ultimate frame within which everything is conceived, the world also needs a human existence to perceive it. Phenomenology thus concedes that the "world" is, in fact, also a part of dasein, human existence. The human world is always a lived world, a life world. Ontology and epistemology are closely interconnected in the phenomenological framework. As Heidegger [13] maintains, "Ontology and epistemology are not two different disciplines which belong to philosophy among others. Both of them characterize philosophy itself, its object and procedure".

People cannot separate them from surrounding social system. Physical residence is for safety, and self-respect and reason to live is given from social environment of relationship and participation in society. Active job activities are needed for the participation and a life story is a way to impose meaning on life, thus connecting individuals to the event. McAdams [14] found that people tended to construct stories as a way to understand life events.

According to Lee [12], the key to the solution of the problem of truth is not the evidential experience, but the communicative action. It is not the evidential experience, but communicative rationality as the formal pragmatic property of discourse that makes the true claim of a statement acceptable. Lee [12] also maintains that; since the constitution of a fact by an evidential experience is open to intersubjective investigation, the intersubjective dimension of constitution is to clarify the condition of the possibility of that constitution.

\subsection{Transcendental Subjectivity}

Subjectivity in life world has various attitudes of religious, ethical, linguistic, social, economic, politic and anthropological. The subjectivity experiences every day as well as something various. The experiences include emotional aspects like love, hate, conflicts or sympathy. Life world subjectivity takes the general thesis of the natural attitude (generalthesis der natürlichen Einstellung). This attitude regards the world as the totality of what exists, and therefore there is nothing beyond the limits of the world.

However, there is something beyond life world like atmosphere. Different atmosphere makes person experience something different: if we are depressed, we feel bored at everything, or if we are active, we feel excited at everything. It means that the experience is not fixed, but made for special meaning for subjectivity by atmosphere. The subjectivity experiences the world as a part of it. Transcendental subjectivity is creative and meaning creation flows endlessly. For instance, the experience in youth is different from that when we are grown up, because the meaning of each moment is different. In conclusion, world of meaning is constituted by the transcendental subjectivity.

This transcendental subjectivity is open to future and thrown away to next time. This subjectivity is called as existence in existential philosophy. Existo, the Latin origin of existence is combination of ex and sisto: ex is 
forward and sisto is to stand, therefore existo is to stand forward. Human being can be exposed as the entire structure of their overall appearance, while at the same time, experienced as the life world subjectivity as well as transcendental subjectivity.

\subsection{Meaningful Life}

There is no doubt that humans are valuable, even though they become old, they deserve worthy life. Worthy and meaningful life is one of human rights. Meaningfulness is different from happiness as Baumeister et al. [15] told in their paper. Happiness is fulfilled when needs are satisfied, but meaningfulness can be made when personal identity and self-expression are possible. According to Husserl [11], meaning is constituted in the life world by transcendental subject. Meaning can be defined as the connection linking two presumably independent entities together. With the stated goal of positive psychology to foster thriving in individuals and render a more fulfilling life, the interest of positive psychology is not to treat patients but to make a normal person's life more fulfilling and for the non-disordered individual to flourish.

Currently, the meaningfulness theory supposes that meaningfulness is a subjective evaluation. Furthermore, meaningfulness is made through positive action, satisfaction with life, the enjoyment of work, happiness, positive affect and hope. Baumeister and Vohs [16] also maintain that meaningfulness is fulfilled through seeking four needs for meaning: sense of purpose, efficacy, value and a sense of positive self-worth.

Meaningful life affects even sickness. A study done by Stillman et al. [17] found that social exclusion results in a perceived loss of meaningfulness in life. When a man thinks himself to be socially excluded, one's sense of purpose, efficacy, value, and self-worth are decreased. Bower et al. [18] found an association between the discovery of meaning and a lower rate of AIDS (acquired immune deficiency syndrome)-related mortality. A study looked into a man who had HIV (human immunodeficiency virus) and witnessed the death of a close friend from AIDS-related death. When confronted with the stress of such a death, those men, who were able to find meaning in the loss, were subject to less rapid declines in CD4 $\mathrm{T}$ cell levels. Then, the subjects who experienced cognitive processing in response to the bereavement were more likely to find meaning in the death of the close friend. Thus, in experiencing a stressful life event, if one is able to engage successfully in finding meaning, there is a potential link to positive immunological benefits and health outcomes.

As there are benefits to making meaning out of life, there is still no one definitive way in which one can establish such a meaning. Those who were successful in creating a meaningful life enjoyed benefits such as higher levels of positive effect, life satisfaction, etc. [19]. When faced with a stressful life situation, finding meaning is shown to help adjustment [20]. Meaningfulness in life is intrinsically related to positive psychology's goal to expand the good life for the normal non-disordered person. It is with a meaningful life that one is able to find connections to people, places, and things.

\section{Conclusions}

This study concerns with aging society and focus on one of the ways to deal with aged society: technical development of ambient robotics, artificial assistance for everyday activities and even professional works easier and self-esteem higher. Elders have relatively weak physical condition, need social welfare system and they should not be excluded from social relations. They are also unchangeable human beings who want to be recognized by other social members.

Meaningfulness is one of essential elements of human beings. We do not need to answer only about how to deal with aged society, but also why. This study finds theoretical background of meaningfulness. The concept of life world and transcendental subjectivity are from phenomenology and become 
ideal foundation for meaningfulness. It is to reflect on background of human beings who constitute meaning in life in the world.

\section{References}

[1] Korean National Statistices Office. 2006. Future Population Estima. Korea: Korean National Statistices Office.

[2] Moon, C. 2002. The Role of Architecture for Healing Environment. Korea: Yeonsei University.

[3] Sirowy, B. 2009. Phenomenological Concepts in Architecture: Towards a User-Oriented Practice. Oslo: Arkitektur-og designhøgskolen (Architecture and Design College).

[4] Monz, A. 2001. Design als Therapie (Design as Therapy). German: Alexander Koch.

[5] Georgoulas, C., Linner, T., and Bock, T. 2012. "Vision Controlled Robotic Furniture System." Gerontechnology $11(2): 370$.

[6] Georgoulas, C., Linner, T., and Bock, T. 2012. “A Multi-robotic Assistant System (MRAS): A Development Approach with Application to the Ageing Society." Gerontechnology 11 (2): 381.

[7] Georgoulas, C., Linner, T., and Bock, T. 2012. "A Novel Mini on Agent Assisted Robotic Kitchen Platform." Gerontechnology 11 (2): 369.

[8] Bock, T., Georgoulas, C., and Linner, T. 2012. "Towards Robotic Assisted Hygienic Services: Concept for Assisting and Automating Daily Activities in the Bathroom." Gerontechnology 11 (2): 362.

[9] Federal Reserve Bank of St.Louis. 2013. "Employed Population: Aged 55-64: All Persons for Each Countries." Accessed December 12, 2013. http://research.stlouisfed.org/ fred2/series.

[10] Lee, N. I. 2004. Phenomenology and Hermeneutics: Transcendental Phenomenology of Husserl and Hermeneutical Phenomenology of Heidegger. Seoul:
Seoul National University Press.

[11] Husserl, E. 1936. The Crisis of European Sciences and Transcendental Phenomenology: An Introduction to Phenomenological Philosophy. Seoul: Hangilsa.

[12] Lee, J. 2004. The Crisis of Modern Life and the World: Husserl's Life-World Concept Study. Seoul: Dongnyeok.

[13] Heidegger, M. 1971. Building Dwelling Thinking. New York: Harper \& Row.

[14] McAdams, D. P. 1996. The Stories We Live by: Personal Myths and the Making of the Self. New York: Guilford Press.

[15] Baumeister, R. F., Vohsb, K. D., Aakerc, J. L., and Garbinskyc, E. N. 2013. "Some Key Differences between a Happy Life and a Meaningful Life." Positive Psychology 8 (6): 1-22.

[16] Baumeister, R. F., and Vohs, K. D. 2002. "The Pursuit of Meaningfulness in Life." In Handbook of Positive Psychology, edited by Snyder, C. R., and Lopez, S. J. Oxford: Oxford University Press, 608-18.

[17] Stillman, T. F., Baumeister, R. F., Lambert, N. M., Crescioni, A. W., Dewall, C. N., and Fincham, F. D. 2009. "Alone and without Purpose: Life Loses Meaning Following Social Exclusion." Experimental Social Psychology 45 (4): 686-94.

[18] Bower, J. E., Kemeny, M. E., Taylor, S. E., and Fahey, J. L. 1998. "Cognitive Processing, Discovery of Meaning, CD4 Decline, and AIDS-Related Mortality among Bereaved HIV-Seropositive Men." Consulting and Clinical Psychology 66 (6): 979-86.

[19] Davis, C. G., Nolen-Hoeksema, S., and Larson, J. 1998. "Making Sense of Loss and Benefiting from the Experience: Two Construals of Meaning." Personality and Social Psychology 75 (2): 561-74.

[20] James, J. M., Scanlan, M. P., Peter, P., Vitaliano, P. Z. J., Savage, M., and Ochs, H. D. 2001. "Lymphocyte Proliferation Is Associated with Gender, Caregiving, and Psychosocial Variables in Older Adults." Behavioral Medicine 24 (6): 537-59. 